\title{
Cultural Aspects and Leadership Effectiveness of Women Leaders: A Theoretical prospective of Saudi Arabia
}

Farheen Akram ${ }^{1}$, Logasvathi a/p Murugiah ${ }^{2}$, Arfan Shahzad ${ }^{3}$

${ }^{1} \mathrm{PhD}$ Scholar, School of Economics, Finance and Banking, Universiti Utara Malaysia, Email: Farheenakram8@gmail.com (Corresponding Author)

${ }^{2}$ Senior Lecturer, School of Economics, Finance and Banking, Universiti Utara Malaysia

Email: logasvathi@uum.edu.my

${ }^{3}$ Senior Lecturer, Othman Yeop Abdullah Graduate School of Business, Universiti Utara

Malaysia, Email: arfan@uum.edu.my

\begin{abstract}
The core aim of this study was to investigate the cultural aspects namely, gender egalitarianism, assertiveness and future orientation of female leaders' effects on their leadership effectiveness. The study explains that cultural aspect of the developed and the Arab countries is different, thus, women leaders in Arab countries face different restrictions, choose different style of leadership and have different future orientations which has significant influence on effectiveness of leadership. The findings of the study revealed that female leaders were less future orientated, less assertive and have limited facilitates as compared to their male counterparts. Hence, leadership effectiveness of women leaders being an important phenomenon was investigated in the Arab countries having male dominance and where women have limited freedom. Moreover, specifically, in Saudi Arabia, women leaders are found in education sector only. Hence, the current study proposed a model to account for the effects of cultural aspects on leadership effectiveness in the education sector.

Keywords: Gender Egalitarianism; Assertiveness; Future Orientation; Leadership Effectiveness.
\end{abstract}

\section{Introduction}

There are different methods for organizations to acquire effective leaders, and so are several means to distinguish effective leaders. Researchers have explored different variables impacting effective organizational leadership like gender and culture (Binns \& Kerfoot, 2011; White \& Özkanli, 2011). Meanwhile, gender and culture are two variables that have received 
much attention in studies on leadership effectiveness, however, limited research provides understanding of gender differences and administrative constraints of women in leadership effectiveness within the culture of the Middle East.

Although women started to be in leadership positions in 1975 , yet the number of women leaders in universities has not changed over during the last ten years (Madsen, 2012). There are different perceptions towards the role of women and men in leadership positions; there is also sex discrimination in hiring women as some studies have mentioned unwillingness of women to accept these positions (White \& Özkanli, 2011, Al-Faez, 2014). Likewise, some studies have mentioned unwillingness of women to accept these positions (White \& Özkanli, 2011, Al-Faez, 2014).

Moreover, women are often not considered for executive positions due to historical management practices, gender stereotyping, inadequate career development and different approaches to negotiation, even though they may be well-qualified for the job. The unfortunate outcome of these practices is that a better qualified female may not be the individual promoted to an executive post. As female managers observe their male counterparts, who may be less qualified, continually receiving salary increases and promotions that they do not deserve. However, females are likely to reticently explore employment opportunities with other organizations, rather than approach their current manager for a better opportunity (Babcock \& Laschever, 2008). Since this is the case, the turnover is inevitable, which can then result in lower organizational performance.

Additionally, women have to be docile and modest as their basic role is that of mother and wife but not as business women (Zakaria, 2001). They are facing disadvantaged due to their traditional role that ultimately limits their participation in the labor market. The issue of the Saudi woman is controversial and complex. In Saudi Arabia Sharia (Islamic) law is followed that is severely criticized by the western scholars which to them is suppressive to the women (Islam, 2014). Huge amount money (around USD 11.9 billion) is held by the Saudi women. Nevertheless, their potential has been undermined by imposing religious, social and political constraints on them by the society. $45 \%$ of Saudi population is constituted of women with the literacy rate of $79 \%$. However, $65 \%$ are employed and $78.3 \%$ unemployed women are university graduates. Saudi Arabia has only $20.1 \%$ (in 2009) labor participation rate which is lowest to her neighboring countries such as UAE, Kuwait and Qatar. Government is the major source of employment and their employment ratio in the private sector is lowest that is only 0.8\% (Al Masah Capital (AMCL), 2010). 
Specifically, in MENA region, Saudi Arabia is touching lowest female labor participation rate. Female labor participation rate in Saudi Arabia is just $18.3 \%$, whereas in Kuwait it is (41.8\%), in Qatar (40.6\%) and UAE (38.4\%).

Thus, this study, the researcher is driving to use the Global Leadership and Organizational Behavior Effectiveness (hereafter: GLOBE) project dimensions to examine the capabilities and leadership skills in the style of leadership for the women in Saudi Arabia. In this study, the researchers focused on the obstacles faced by the women in the kingdom of Saudi Arabia in order to promote them up to the chancellor level position in the universities and colleges.

\section{Literature Review}

Leadership has been a topic of research interest for many years. Early leaders in the research in this field were psychology scholars, such as Stogdill and Shartle (1948), House, Spangler, and Woycke (1991) and social scholars such as Tannenbaum and Massarik (1957) and Stogdill (1950). In the 80s and 90s, researches such as Bass (1985, 1990, and 1997), Hollander and Offermann (1990) postulated that leadership should empower followers more and they are called for more followers' participation in leadership. What follows is an overview of seminal research in the study of leadership (Alhourani, 2013). He asserted that leadership is an interaction between leaders and followers, not an individual characteristic in the leader. He assumed that leadership is an interaction between people who undertake activities to move them towards a shared goal. Stogdillet and Shartle (1948) argued that all the Individuals in an organization, both leaders and followers, are responsible for the good of the company, and must show their best performance for the organization to be effective. Thus, leaders should encourage their followers to participate in the success of the organization $(\mathrm{Li}$, 2010). Moreover, a leader has a responsibility to make all followers show their best performance to attain the goals of the organization (Owusu, 2011).

To enhance the efficiency and to attain the goals of a firm, leadership is considered as a key role of management. According to the Management Study Guide MSG (2015), importance of leadership is as under: Initiates Action: A person who takes the initiative to start work and communicate the real goals and policies of the firm to the employees to achieve these goals and also provide assistance to start work is known as Leader. Motivation: A leader demonstrates a motivated role in the relative operations. He encourages the workers with monetary and non-monetary outcomes and thereby grows the work from the workers. 
The MSG (2015) added the providing guidance: The responsibility of leader is not only to organize the employees but also perform a supervisory role for the workers. Guidance means coaching the juniors about techniques which they have to accomplish their assignment efficiently and competently. Creating confidence: Confidence is a chief factor that can be attained through communicating the work determinations to the assistants; clarify their role, and provide guiding principle to achieve the organizational goals. It is too significant to listen from the employees with respect to their grievances and difficulties. Building morale: Morale represents the collaboration of the workforces concerning their work and receiving them into self-confidence and winning their belief. A leader can also perform as a morale promoter by accomplishing complete cooperation so that the performance of employees is improved, and they may utilize their skills as they work to attain the organizational goals.

Lastly, the other significant factors of leadership are Builds work environment: Employees do things for Management. A sound growth of an organization is required a wellorganized work environment. Hence, human associations should be preserved into concentration by a leader. He must maintain personal contacts with workers and should pay attention to their complications and try to resolve. He has to deal with employees in a caring way. C-ordination: Coordination can be done through reconciliation of the employees' own interests with managerial goals. This management can be attained through appropriate and real association with employees that should be prime aim of a leader (MSG, 2015).

A systematic understanding is required by leader to determine the key factors of organizational culture, and its impact, therefore, they can connect new vision and approve followers' obligation (Schein, 1997). Leaders perform a noteworthy role in determining as well as in the preservation of the organizational culture. It is in the leadership procedure that the outcome of culture turns into greatest appreciable acts. The leadership mobilizes consideration in the direction of a new idea; it is the corporate culture that discusses validity on that idea (Schein, 1997). Therefore, it can be supposed that organizational culture is intensely noted and shares a cooperative association (Binns \& Kerfoot, 2011). Leadership in the context of culture refers to the prerequisite conditions and ideal attitudes required for governance. Schein (1997) claims that the only thing related to the real importance of leaders is to create and manage culture. Although Schein (1997) is referring to organizational culture in this quote, the inference is that the endorsed traits of the leaders are a reflection of organizational values. 
Pakistan Journal of Humanities and Social Sciences, 5(1), 2017

Hofstede (1991) described how culture has the ability to program the minds so that individuals take on or accept specific values and exhibit specific behaviors. Hofstede in his study recognized five worldwide extents for numerous cultures. Those extents were Power Distance, Uncertainty Avoidance, Short/Long term Coordination, Masculinity/Femininity, and Individualism/Collectivism. Thus, the level of masculinity and femininity was determined by the culture, and this dimension would show gender differences in leadership between different cultures.

Assertiveness refers to the degree to which people are assertive or non-assertive, aggressive or non-aggressive, and tough or tender in social relationship (House et al., 2004). The concept of assertiveness originates in part from Hofstede's (1998, 2001) culture dimension of masculinity versus femininity. In masculine cultures, men are supposed to be self-assured and strong whereas females are shy and affectionate. Hofstede (2001) explicitly links his tough-tender dimension in terms of values to sex roles and gender equality even if this index has no items mentioning assertive attributes or behaviors.

In this positive vein, being assertive has been shown to be a desirable personality trait for certain occupations. For example, assertive state police officers were found by their supervisors to be more effective in their duties than non-assertive police officers (Mills \& Bohannon, 1980). Likewise, assertive military officers in training were perceived by their instructors more often as leaders than the non-assertive officers (Boldry, Wood \& Kashy). Students graduating from military training were found to be more assertive, more likely to be persuasive leaders, and more prone to like supervisory activities than individuals just entering the same training program. On the other hand, subordinates in some occupations, such as nursing, may view assertiveness as an undesirable quality.

Despite these differences, a common theme in these findings is the idea that assertive individuals make things happen. Assertive individuals clearly are not passive. As such, a key concept of leadership is assertiveness, which means that some personal action is always taken that serves to provide a strategy to achieve a defined goal (White \& Özkanli, 20110. In light of the discussion above, assertiveness has been found to have both a positive and a negative relationship to leaders as assertiveness also predicts leadership effectiveness.

The concept of gender egalitarianism and related constructs can be very complex. There are many antecedents that drive cross-cultural differences in the division of roles between the sexes (House et al., 2004). Antecedents include attitudes, stereotypes, parental investment, religion, economic development and even climate and geographical latitude. To 
add to the complexity, some studies within a particular area sometimes yield contradictory findings. Even though promoting gender equality, GLOBE study reveals to the strength to which an organization or a culture reduces gender role alterations while endorsing gender equivalence (House et al., 2004).

Hofstede $(1998,2001)$ studied this concept in terms of the emphasis that societies place on masculinity and femininity. Masculine values are related to assertiveness, success, and competitiveness while feminine values are linked to nurturance and solidarity. In addition, he studied the differences among societies in terms of what they viewed as appropriate behaviors for males versus females.

Kreiser, Marino, Dickson, and Weaver (2010) conducted a study of 1048 companies around the six countries to identify the influence of national culture. Several organizations that characterize the national culture mainly depend on dual basic extents. In this study, Individualism and masculinity were not described by the author as a vital factor. In investigative point of view the association among cultural values and positive behavior of firm was not found significant.

Adler (1986) tried to show a general perspective about the situation of female leaders and the barriers that hinder them from advancement. Adler found the difference in the women's contribution in the employment between various countries in the globe. The author claimed that women's participation in the labor force was lower in the Middle East than that was in the Western world. Adler explained that the difference in rate of women's participation in the labor force was because of social, educational, and legal reasons (Al-Hourani, 2013). Moreover, Adler (1986) also suggested that in spite of the high rate in women's participation in labor force in many countries, there was under representation in top management for women. This under representation of women in management positions was recognized in all cultures (Adler, 1986). There were cultural, social, legal, educational, historical, and psychological barriers. Adler also asserted that there was an increase in the number of women mangers, but it was a slow increase, because of recognition that women in management were perceived differently, and because they were perceived to contribute less than men in the field of management. Such perceptions cause women face struggles to take their right to advancement to leadership positions as Burns (1987) discussed in his study.

According to House et al. (1999), future orientation is the level to which a collectivity inspires and rewards future-oriented attitude like as planning and deferring delight. It has been recognized steadily as a core value orientation of entire cultures (Kreiser et al., 2010). 
Literature on future orientation can be divided into three perspectives. The first is using a cross-cultural perspective at the societal level which closely ties time perceptions and attitudes to important outcomes such as economic success or overcoming other health or socio-economic societal barriers. Future orientation appears to be developed during childhood and adolescence and is linked to the process of socialization (House et al., 2004). In general, most societies are reported to have moderate levels of future orientation practices giving near equal priorities to futuristic concerns as to immediate issues (House et al, 2004).

The GLOBE investigation determined propensity of organizations with reference to the culture of high future bearings to be persuaded to hold assured leadership styles: Participative, Team-Oriented, Humane-Oriented, and Charismatic/Value-Based (Dorfman et al., 2004). GLOBE's leadership theory categorized "other-oriented" match up with this distinct servant leadership trait. As GLOBE originates leadership traits that would be desired by groups in the highly future oriented cultures, numerous of which have been discovered as part of the servant leadership concept (together with distinctive characteristic). This study described the more comprehensive investigation of servant leadership and how it communicates to future orientated culture, will approve that the degree of cultural future orientation disturbs the choice of groups for servant leadership behaviors.

Several facets of allocation the necessities of followers need servant leaders to take an innovative method in their connections with groups. Correspondingly, Liden, Wayne, Zhao and Henderson (2008 specified, "Servant leadership be different from traditional methods to leadership in that it strains personal reliability and emphases on developing strong long-term relations with employees". It is not credible that groups from cultures with complex levels of future orientation, where long-standing line of business planning and individual proficient development are significant and appreciated, would have a propensity to surely hold and react to servant leader behavior that is concentrated in part on emerging groups for long-term professional success.

\section{Discussion}

Relationship between leadership effectiveness, gender egalitarianism, assertiveness and future orientation has been well established and discussed. The existing literature reveals that leadership effectiveness significantly influences through the leadership style of leaders. However, leadership style varies between male and female leaders. Female leaders prefer distinct leadership style than male leaders. Similarly, male and female have different future orientations that has significant effect on leadership effectiveness. Leaders with long future 
planning or orientation act differently since they try to develop long-term relations to secure the jobs. Owing to the cultural differences female in Arab countries have low future orientation because they need to focus on their other responsibilities. Females in different cultures have different priorities, thus, findings of other studies from developed countries are not generalizable in the Arab countries like Saudi Arabia. Additionally, assertiveness among female directors is low when it comes to the level of assertiveness among male leaders. Hence, female leaders' assertiveness strongly influences the leadership effectiveness in different ways. Moreover, a certain level of assertiveness is required in some occupations and in some cases, it is a symbol of effectiveness.

\section{Conclusion}

The current study aimed to investigate the leadership effectiveness of female leaders in higher education of Saudi Arabia. While digging into the literature, the researchers of the study found that Arab females are facing a lot of challenges on job due to cultural changes. Additionally, they have different leadership behavior, aggressiveness as well as future orientation. Concerning these problems, researchers attempted to investigate and examine the Arab women leadership characteristics but unable to reach any specific decision. As most of these studies followed the pattern of research done in the developed countries. Hence, the current study has designed to investigate the Arab women leaders from a different perspective. The current study also found that if the government supports the female leaders and provides security and facilities at the work place, female leaders' effectiveness will enhance. Thus, the current research investigated the leadership effectiveness in the presence of the government support. The proposed theoretical model of the study is exhibited in Figure 1.

\section{Figure 1: Research Framework}

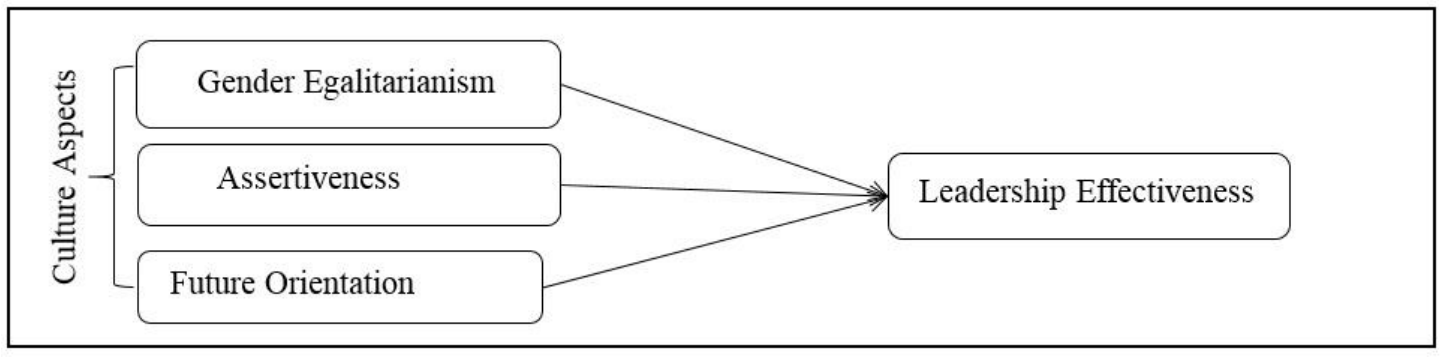


Pakistan Journal of Humanities and Social Sciences, 5(1), 2017

\section{References}

Adler, N. (1986). Women in management worldwide. International Studies of Management \& Organization. Fall/Winter86/87. 16 (3/4). 3-32.

Al-Faez, H. (2014). The Administrative Empowerment of Women Leaders in Saudi Universities- Reality and Challenges. Research Paper to Government Administrative

Al Masah Capital Limited. www.almasahcapital.com

Babcock, L., \& Laschever, S. (2008). Is talent going to waste in your company? Harvard Management Update, 13(7), 3-4.

Bass, B. M. (1997). Does the transactional-transformational leadership paradigm transcend organizational and national boundaries? American Psychologist, 52(2), 130-139.

Bass, B. M., \& Avolio, B. J. (1990). Multifactor leadership questionnaire.

Bass, B. M. (1985). Leadership: Good, better, best. Organizational Dynamics, 13(3), 26- 40 .

Binns, J., \& Kerfoot, D. (2011). Editorial: Engendering leadership: Dedicated to the spirit and the scholarship of the late Joan Eveline. Gender, Work, and Organization, 18(3), 257-262.

Boldry, J., Wood, W., \& Kashy, D. A. (2001). Gender stereotypes and the evaluation of men and women in military training. Journal of Social Issues, 57(4), 689705.

Burns, M. J. (1987). Introduction. Human Resource Management (1986-1998), 26(2), 153.

Dorfman, P. W., Hanges, P. J., \& Brodbeck, F. C. (2004). Leadership and cultural variation. In R. House, P. Hanges, M. Javidan, P. Dorfman \& W. Gupta (Eds.), Culture, Leadership, and Organizations: The GLOBE Study of 62 Societies (pp. 779-719). Thousand Oaks, CA: Sage.

Hofstede, G. (1991). Cultures and organizations: The software of the mind. New York: McGraw-Hill. 
Hofstede, G. (1998a). Attitudes, values and organizational culture: Disentangling the concepts. Organization Studies, 19(3), 477-493.

Hofstede G. (2001). Culture's Consequences: Comparing Values, Behaviors, Institutions, and Organizations across Nations (2nd ed.). Thousand Oaks, CA: Sage

Hollander, E. \& Offermann, L. (1990). Power and leadership in organizations. American Psychologist. 45, (2). 179-189.

House, R. Spangler, W. \& Woycke, J. (1991). Personality and charisma in the U.S. presidency: A psychological theory of leader effectiveness. Administrative Science Quarterly, 36(3), 364-396.

House, R. J., Hanges, P. J., Javidan, M., Dorfman, P. W., \& Gupta, V. (2004). Culture, leadership, and organizations: the GLOBE study of 62 societies. Thousand Oaks, CA: Sage.

House, R. J., Hanges, P. J., Ruiz-Quintanilla, S. A., Dorfman, P. W., Javidan, M., Dickson, M. W., Gupta, V. (1999). Cultural influences on leadership and organizations: project

Islam, S. (2014). Saudi Women: Opportunities and Challenges in Science and Technology. Education Journal. 3 (2). 71-78.

Kreiser, P. M., Marino, L. D., Dickson, P., \& Weaver, K. M. (2010). Cultural influences on entrepreneurial orientation: The impact of national culture on risk taking and proactiveness in SMEs. Entrepreneurship Theory and Practice, 34(5), 959-983.

Li. Y. (2010). A Comparison of the Cultural Impacts on Leadership Preferences between Overseas Chinese Petroleum Professionals and Globe Scores. Dissertation. ProQuest LLC.

Liden, R. C., Wayne, S. J., Zhao, H., \& Henderson, D. (2008). Servant leadership: Development of a multidimensional measure and multi-level assessment. The Leadership Quarterly, 19 (2), 161-177. 
Madsen, S. R. (2012). Women and leadership in higher education: Learning and advancement in leadership programs. Advances in Developing Human Resources, 14(1), 3-10.

Mills, C. J., \& Bohannon, W. E. (1980). Personality characteristics of effective state police officers. Journal of Applied Psychology, 65(6), 680.

Owusu, H. (2011). Using the Globe Study to Explain How Culture Affects Leadership. Dissertation. ProQuest LLC.

Schein E. (1997). Organizational Culture and Leadership. San Francisco: Jossey Bass.

Stogdill, R. M. (1948). Personal factors associated with leadership: A survey of the literature. Journal of Psychology, 25, 35-71.

Stogdill, R. M. (1950). Leadership, membership and organization. Psychological Bulletin. January,Vol.47, No.1, 1-14.

Tannenbaum, R. \& Massarik, F. (1957). Leadership: A frame of reference. Management Science. October, 4 (1), 1-19.

White, K., \& Özkanli, Ö. (2011). A comparative study of perceptions of gender and leadership in Australian and Turkish universities. Journal of Higher Education Policy and Management, 33(1), 3-16.

Zakaria. Y. (2001). Entrepreneurs at Home: Secluded Muslim Women and Hidden Economic Activities in Northern Nigeria. Nordic Journal of African Studies, 10(1) 107-123. 